\title{
基于多学科数字技术应用的山地型城市设计实践 以重庆前沿科技城为例
}

\author{
A Mountainous Urban Design Practice Based on Multidisciplinary Digital Technologies: \\ Study on the Case of Chongqing Frontier Science City
}

摘要: 城市设计作为一种引导城市空间营造行为的技术实践, 具有系统性、开 放性和丰富性的特征。现代城市设计面临的挑战如此复杂, 已远超传统的空 间美学范畴, 需要融入众多相关学科和工程技术, 尤其是数字技术, 推动城 市设计工作更为综合和科学。本文以重庆前沿科技城城市设计为例, 探索在 山地型的城市建设区, 如何在满足合理建设强度, 并承载既定发展目标的同时, 针对山地环境特点, 抛弃强力改造地形的常规手法, 探索低影响开发的各种 手段; 并研究如何依靠现代的可量化技术工具, 有效降低工程成本, 综合达 成产业、宜居、活力、高效、生态、节能、智慧等多元化诉求。这一方面为 城市设计影响、完善甚至修改法定规划提供了强大的技术支撑; 另一方面也 为城市设计有效引导后续具体的开发实践提供了重要的技术依据。案例中运 用的可量化技术工具涉及山水空间、生态保护、安全保障、海绵城市、市政 能源以及风环境模拟等方面。

Abstract: As a technical practice guiding urban space (re)creation, urban design is characterized by systematicness, openness and richness. Modern urban design is facing growingly complex challenges, far beyond the scope of traditional space aesthetics, and needs to integrate many related disciplines and engineering technologies, especially digital technologies, which make the urban design work more comprehensive and scientific. The paper studies on the urban design of Chongqing Frontier Science City. Instead of using conventional way of strong terrain transformation, the plan explores various means of low impact development (LID) to meet reasonable construction density and development goals. The paper also studies on modern quantifiable technical tools to reduce the cost and meet diversified demands in industry, livability, vitality, efficiency, ecology, energy conservation and intellectualization. Consequently, urban design provided strong technical support to influence, fulfill and even modify statutory planning; meanwhile, it is equipped with important technical basis to guide subsequent engineering practice effectively. The quantifiable technical tools used in the case involve landscape space, ecological protection, safety guarantee, sponge city, municipal energy and wind environment simulation, etc.

关键词: 数字技术; 山地型城市设计; 重庆

Keywords: Digital Technology; Mountainous Urban Design; Chongqing

作者: 徐刚, 清华大学建筑学院博士研究生; 北京清华同衡规划设计研究院有限 公司副总规划师, 教授级高级工程师。archxu@126.com 毛羽, 北京清华同衡规划设计研究院有限公司, 工程师
引言

城市设计作为一种引导人居空间营造行为的技术 实践, 具有悠久的历史。长期以来, 它作为协调人与 自然的关系、营造良好人居环境的一种有效手段, 无 论在东方还是西方, 均有丰富的经验积累。中国古代 学者管仲在《管子. 乘马》中就提出了 “因天材, 就 地利, 故城廓不必中规矩, 道路不必中准绳” 的自然 至上理念, 体现了传统营城观念中因地就势利用的哲 学思维。英国园林设计师麦克哈格在《设计结合自 然》一书中, 强调土地利用应遵从其自然固有的价值 与自然过程, 遵从其生态学可持续性特征, 体现了现 代设计思想中的科学思维 ${ }^{[1]}$ 。

选择山地营造人居空间, 部分出于防卫或礼仪需 要, 更多则是人多地少、人地矛盾突出的地区不得已 而为之的一种选择。我国是一个多山的国家, 山地面 积占国土面积的三分之二, 山地城镇占全国城镇总数 的一半以上, 山区人口占全国总人口的一半左右。在 长期的农业社会历史中, 人类敬畏自然、追求与自然 和谐共处。进人工业社会以后, 我国城市化进程加速, 人口、产业、资源迅速积聚, 用地扩张、开发强度空 前, 这种趋势在以重庆等为代表的山地城市概莫能外; 以空间为标尺, 山地特有的自然条件决定了很难复制 平原地区的建设经验; 以时间为标尺, 工业社会逐步 向知识经济时代迈进, 人口、产业、资源的分布特征 发生了重大变化。

如何有效应对上述挑战, 探索一套针对特定山地 自然条件的人居环境建设理念与模式? 本文拟结合重 庆前沿科技城的设计实践, 借助多学科数字技术应用, 探讨一种解题之道。 


\section{1 数字化设计手段研究与应用概况}

\section{1 国内概况}

数字化技术在国内规划设计中的应用方兴未艾。在不同 的专业方向上, 各种应用研究精彩纷呈。李苗裔等人以传 统城乡规划流程为基础, 从规划数据生命周期的视角, 借 助数字技术构建了一套数据驱动的规划技术支持框架 ${ }^{[2]}$ 。曹 有新将三维激光扫描技术、GIS 历史切片等技术应用到城市 历史遗产领域 ${ }^{[3]}$ 。高海峰研究利用 Skyline 软件进行二次开 发, 结合 ArcGis 在分析查询方面的成熟技术和 3DGIS 在空 间显示方面的优势, 尝试建立二三维一体化的规划辅助决 策系统 ${ }^{[4]}$ 。蔡凌豪以数字化设计方法解析风景园林专业的定 义、特征和概念谱系, 并尝试构建应用软件平台 ${ }^{[5]}$ 。清控人 居环境研究院开发了城市排水管网模拟系统 (Digital Water Simulation)。此外, 陈学楷、朱宁等人在工业遗产研究领域 ${ }^{\left[{ }^{6}\right]}$, 卢继芳、刘义勤等人在地下空间设计实践, 谭瑛等人、张 赫等人在历史空间解译 ${ }^{[7]}$, 赵珂、郑晓华等人在调查研究环 节, 均从实际需求角度, 创造性地应用了各类数字化技术 手段 ${ }^{[8,9]}$ 。

具体到城市设计研究实践, 杨俊宴提出将数字化技术应 用到城市设计相关的全流程，包括采集、调研、集成、分析、 设计、表现、管控七个方面 ${ }^{[10]}$; 杨滔将空间句法应用到城市 设计, 重视空间概念在数字虚拟世界与真实世界之间的体验 和理解, 定量地模拟并研究物质空间形态构建 ${ }^{[11]}$ 。

\section{2 国外概况}

通过科学软件工具支撑设计和工程实践, 西方国家积累 了丰富的经验。ArcGIS (地理信息系统软件平台)、Skyline (三 维地理信息软件)、Civil3D (土木工程道路与土石方计算软 件)、InfraWorks（适用于土木基础设施规划和设计的 BIM 连接平台)、Fragstats（景观格局指数计算软件）、Phonics（建 筑流体模拟软件）等应用广泛。

另一方面, 不少学者致力于利用数字技术进行智能规划 设计。布莱恩 - 麦格拉思 (Brian McGrath) 把城市设计理论 与城市信息地图绘制、建模及 $3 \mathrm{D}$ 仿真结合在一起, 作为理 解城市随时间流变、分化的一个方法 ${ }^{[12]}$ 。克里斯蒂安 - 德里 克斯（Christian Derix）尝试将传统的经验性的专业知识进行 编码, 使之成为模拟数据, 通过输人特定的设计要点, 借助 “元启发式算法” (meta-heuristic algorithms) 来生成定制化 结果 ${ }^{[13]}$ 。恩里克塔 - 利亚夫雷斯 (Enriqueta Llabres) 提出建 立具有内在相关性的城市模型 (relational urban models), 城 市参数的模拟更接近真实的复杂性 ${ }^{[14]}$ 。这些方法偏重于 “模 拟”和 “算法”, 强调结果的 “理性”。

\section{2 数字化城市设计基本理念}

\section{1 应对复杂山地条件的精细设计理念}

山地城市脆弱的自然生态环境和复杂地形地貌特征使得 山地城市规划设计较平原城市要复杂得多。目前山地城市规 划采用的工具普遍较为传统, 虽然已经由二维设计向三维设 计转变, 但是对实际建设时产生的工程量、建设后生态效益 保护情况等因素仍缺乏能够精细测算的工具, 难以保证规划 方案的可实施性。因此山地城市设计急需引入新的技术工具, 让设计师以数字化三维技术为平台, 基于规划先期设定的各 项参数目标, 实现方案调整、成果指标即时互动, 以及多专 业的协同精细化作业。

\section{2 强调多专业协同的科学设计理念}

山地城市作为一个复杂的相互作用的系统, 其珍贵的自 然资源还包括独特的山水景观、精细的生态循环系统、复杂 的地形地貌, 这些都应纳人低影响开发的研究范畴。因此建 立一整套针对中高强度山地城市低影响开发的系统性策略尤 为重要, 这需要多个专业高度协同, 在低影响开发的前提下 实现功能、交通、景观、生态、水文、能源、坚向等各个子 系统的协调发展。

\section{3 基于需求供给匹配的人本设计理念}

传统的设计无法精准辨别使用人群类型以及相应的差异 性需求, 呈现出粗放特征。随着大数据的发展, 以人为单位 的精准定位手段日趋成熟, 为设计提供了扎实的数据研究基 础, 使以人为核心的设计更加有据可依，有法可操。

\section{4 基于动态评估反馈的持续设计理念}

以往的规划设计实施评估多基于原有控规指标进行, 评 价偏重于方案的实施程度, 而对于成果本身的好坏缺乏评 价。城市设计需要从管理者与使用者的角度出发, 以绿色 友好、舒适健康、多元活力为目标, 构建关键绩效指标 (KPI Key Performance Indicator）体系，为项目的后续评估建立操 作依据。

\section{3 数字化技术平台}

\section{1 数字技术支持场地设计}

\subsection{1 项目概要和场地现状条件}

重庆科学城规划定位为西部地区开放合作先导区, 重庆 市科技创新引领区; 规划用地范围约 $21 \mathrm{~km}^{2}$, 建设用地总量 $11.79 \mathrm{~km}^{2}$ ，规划建设量 1096 万 $\mathrm{m}^{2}$ ，规划年产值 1200 亿元。 重庆科学城用地地形特征丰富、条件复杂。现状平整用 
地极少, 高程最大差值超过 $300 \mathrm{~m}$ 。5 条山脊线呈指状伸展, 平均高度约 $300 \mathrm{~m}$, 冲沟纵横, 水塘密布, 两条水系横贯东 西（图 1)。

\subsection{2 传统场地设计手段}

传统设计手段通常采用以下做法 : 为了最大化挖掘可建 设用地资源, 大尺度平整场地, 破坏地形丰富性 ; 为了支撑 均一化空间布局和高强度开发，采用常规的网格化道路网系 统, 交通体系割裂场地特性, 交通方式单一化, 破坏地质稳 定性; 伴随而来的大量填挖方工程, 破坏生态系统, 提升工 程造价，破坏了场地内丰富的空间特征（图 2)。

\subsection{3 基于 ArcGis 和 Civil 3D 技术支持的场地设计}

本次城市设计方案以 Autodesk Inforwork 数字化三维设 计为平台, 该平台可以实现平面空间布局设计与道路场地竖 向的同步设计，并即时生成土方工程量计算结果。通过多方 案比较, 选取经济、生态、安全、景观效益最优的方案, 并

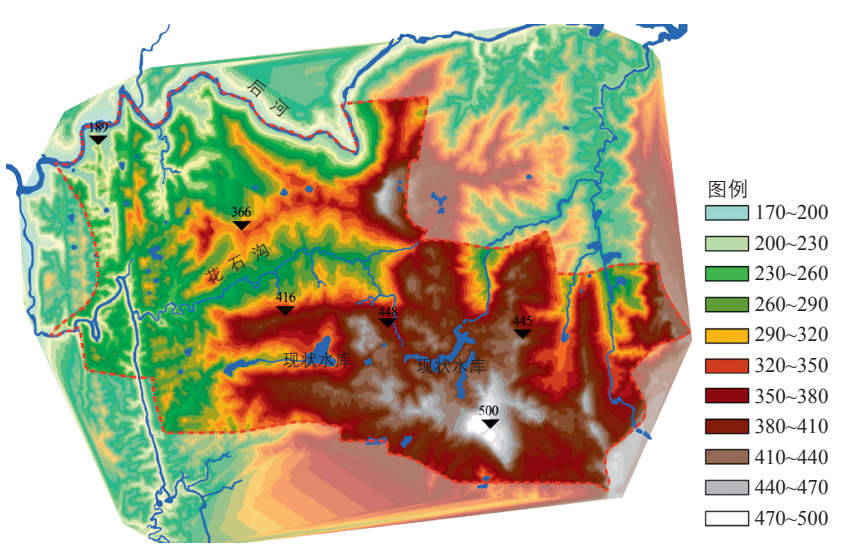

图 1 现状高程图

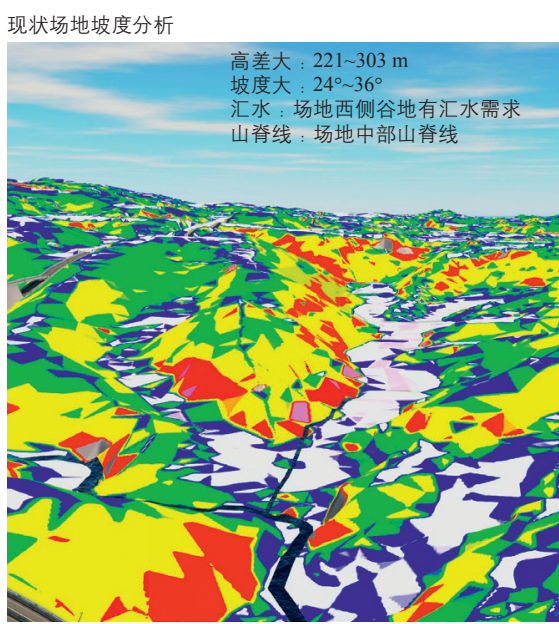

原规划方案初算值

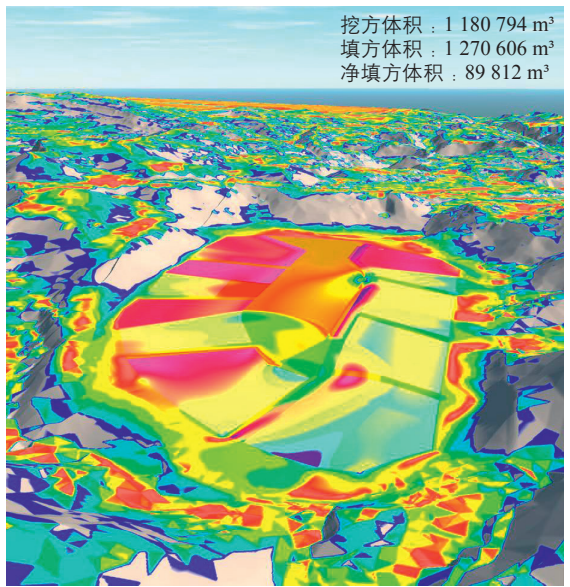

对最终方案进行工程量测算评估。通过即时互动, 量化度 测的数字化精细设计, 实现本方案在实施工程上的合理性

(图 3, 图 4)。

借助该软件, 本次规划与原有法定规划相比土方工程量 减少 4457 万 $\mathrm{m}^{3}$, 约 53\%, 可节省将近 26.7 亿元的土方造价。

\section{2 数字化三维空间形体设计}

\subsection{1 传统三维空间形体设计}

传统三维空间设计都是在平面方案完成后, 借助实体模 型完成空间形态的推敲, 这种三维设计方式主要关注模型的 整体鸟瞰形体, 对建设后实际产生的空间感受缺乏关注, 缺 少人性尺度的空间分析。

\subsection{2 基于 3D GIS 和 Skyline 技术支持的三维空间形体设计}

本次设计以 3D GIS 为基础, 通过 Skyline 对方案空间模 型进行分析, 确定空间地标和观景点, 模拟人的视野, 分析 视野通透程度, 校核观景点地标位置, 以及视线廊道两侧的

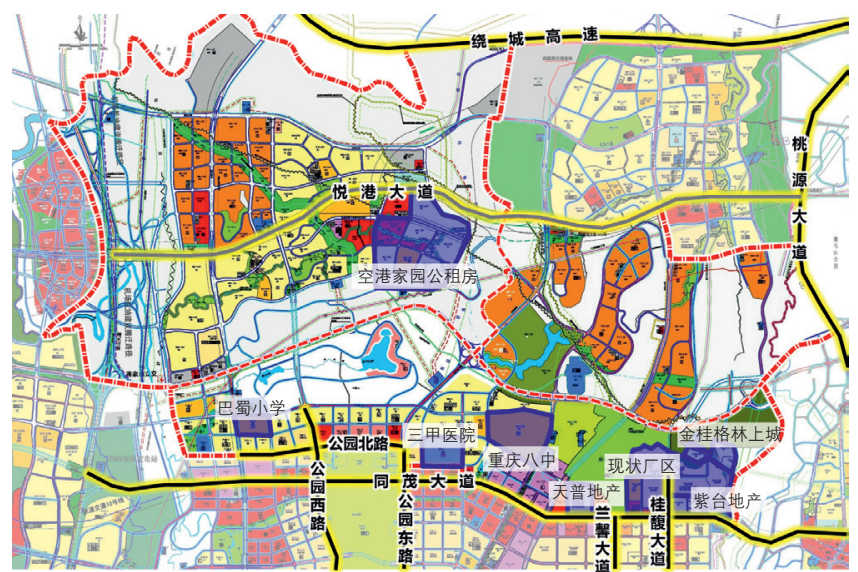

图 2 原有控规图

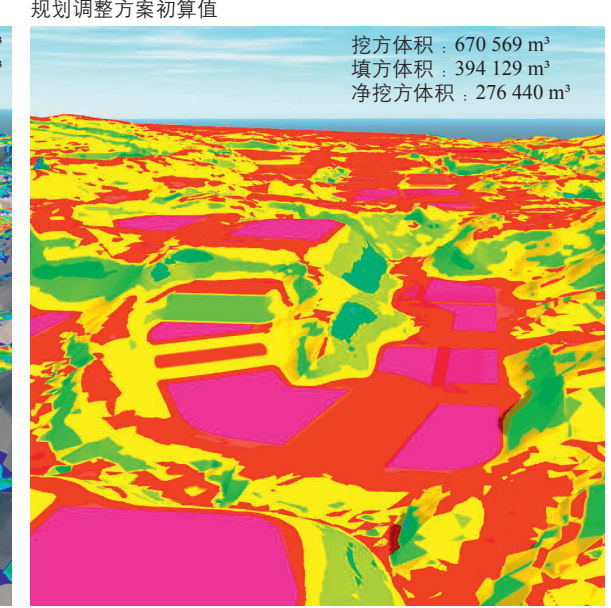

图 3 场地坚向土方分析图 
建筑体量（图 5)。

\section{3 大数据支撑的公共服务设施供给}

\subsection{1 传统的公共服务设施需求预测及供给模式}

传统的以常住人口总量需求为导向进行公共服务设施配 给, 忽略了不同类型人群的多元化公共设施需求, 造成公共 服务资源配套的不平衡。近年来公共设施规划越来越关注精 细化的供给方式, 通过大数据分析, 针对不同人群的需求实 现公共服务设施的有效供给。

\subsection{2 大数据支撑的公共服务设施需求预测及供给模式}

方案定位重庆前沿科技城，未来将聚集全国科技创新的 企业和研究机构, 因此以创新阶层为目标人群, 通过大数据 的方式研究创新阶层的生活方式、工作方式和出行规律等, 精准定位目标人群的需求, 通过定制式的公共服务配给, 创 造最具吸引力的环境 (图 6)。

基于对中关村等知识人群聚集地的长期数据跟踪研究, 本方案分析使用的数据除了《中关村指数》《硅谷指数》等 公开来源, 还包括《中关村街道人群活动特征大数据评估与
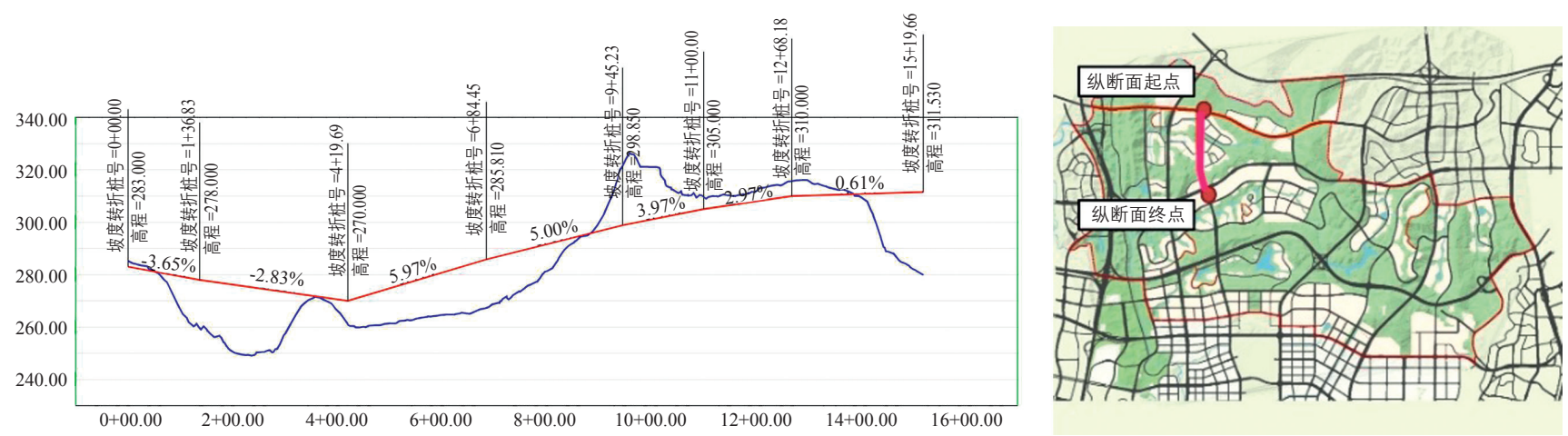

图 4 道路坚向土方分析图
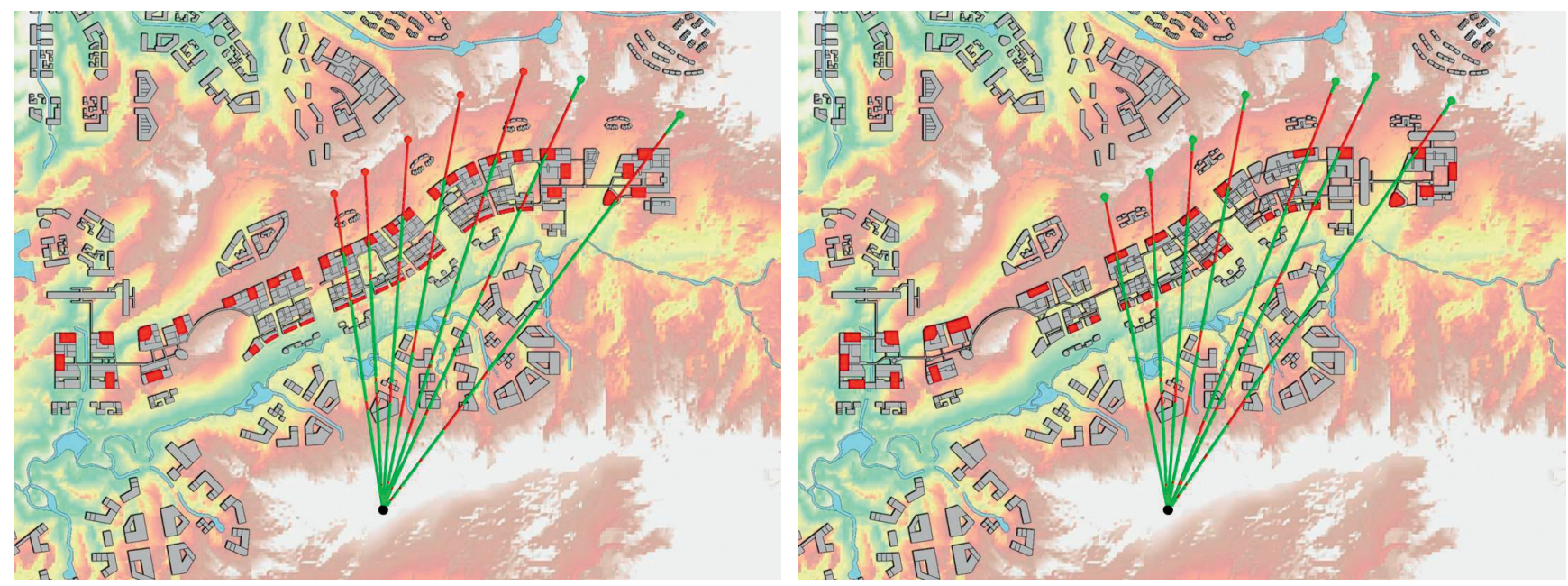

图 5 视线廊道分析
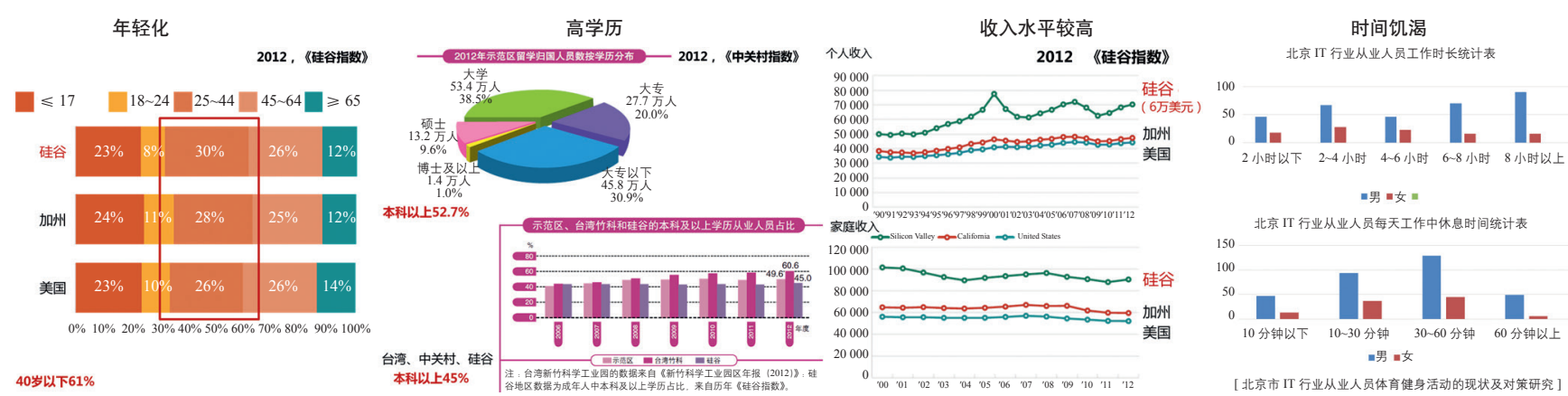

图 6 人群特征分析 
调整建议》《共享单车春季出行报告》《学区房研究》。通过 数据分析, 最终对地区办公服务类型、教育设施配比、职住 空间配比、商业文体配套等内容提供定制化方案。

\section{4 数字化能源系统设计}

\subsection{1 传统的能源供应系统}

传统的能源规划多基于传统用能方式测算能源供给, 清 洁能源的使用多局限于建筑单体层面, 而如何实现清洁能源 与传统市政能源的供给结合，如何系统化实现城市或地区节 能, 尚缺乏有效手段。

\subsection{2 基于绿色科技、精细模拟的能源供应系统}

近年来绿色发展已经上升到国家发展战略层面, 各地的 环保要求日趋严格, 对清洁能源的使用也备受重视。在此背 景之下, 本次设计选取了更加符合自然条件的小型分散式再 生能源供给方案, 优先根据现状自然特征确定再生能源供给 方式。

根据方案中不同的功能分区, 结合具体地块建筑功能, 计算能源需求，由不同分区的区位特征和能源需求确定能源 供给的组合方案。最终的能源规划方案与常规能源方案相比, 减少了将近 $25 \%$ 的 $\mathrm{CO}_{2} 、 \mathrm{SO}_{2} 、 \mathrm{NOx}$ 的排放量（图 7)。

\section{5 数字化雨洪管理}

规划区位于嘉陵江水系, 大区域水环境敏感, 水资源较 为丰富。规划区内山体坡度大, 地表径流速度快、破坏力强, 易形成山洪灾害; 另外由于径流速度快, 冲刷力强, 水体面 源极易受到污染。

\section{5 .1 传统的排水模式}

传统方式以 “排”为主导, 依靠传统的大口径市政管网 来解决山地雨洪问题, 易造成水资源和管网投人的浪费, 以 及生态系统失衡, 而局部地区的海绵城市措施又难以实现区 域整体的低影响开发; 因此, 设计方案需要在区域层面提供 系统的雨洪管理策略和精准量化的雨洪管理措施, 并在各个 地块中实现落地。

\subsection{2 基于 DigitalWater Simulation 技术支持的数字化雨洪管理}

首先设定规划目标, 即开发后的径流量接近开发前的径 流量。基于汇水区地形和现状下垫面构建地表产汇流模型, 将规划区划分为 129 个子汇水区, 利用城市排水管网模型软 件, 模拟得出设计场地近 3 年内的年径流控制率, 最终设定 年径流总量控制率为 $80 \%$ (对应设计降雨量 $25.5 \mathrm{~mm}$ )。

通过蒙特卡洛随机采样法, 在用地方案的基础上, 对设 计方案中 541 个地块的各类低影响开发设施的建设比例、开 发强度等因素进行综合计算评估, 篮选出满足控制目标的有 效方案集合。确定优选方案中各个地块的下沉绿地率、绿色 屋顶率、透水铺装率、植草沟率、雨水桶个数、生物滞留池 率等措施控制参数, 从而指导各个地块的建筑、景观、场地 等空间设计（图 8)。

\section{6 数字化生态效益模拟}

\subsection{1 传统设计缺失生态效应评测}

传统生态设计环节主要基于生态敏感性要素进行分析, 包括水体、林地、高差等, 对于场地内的生物多样性分析较 少。本次生态设计引人景观生态学的理念, 对 31 个生态影
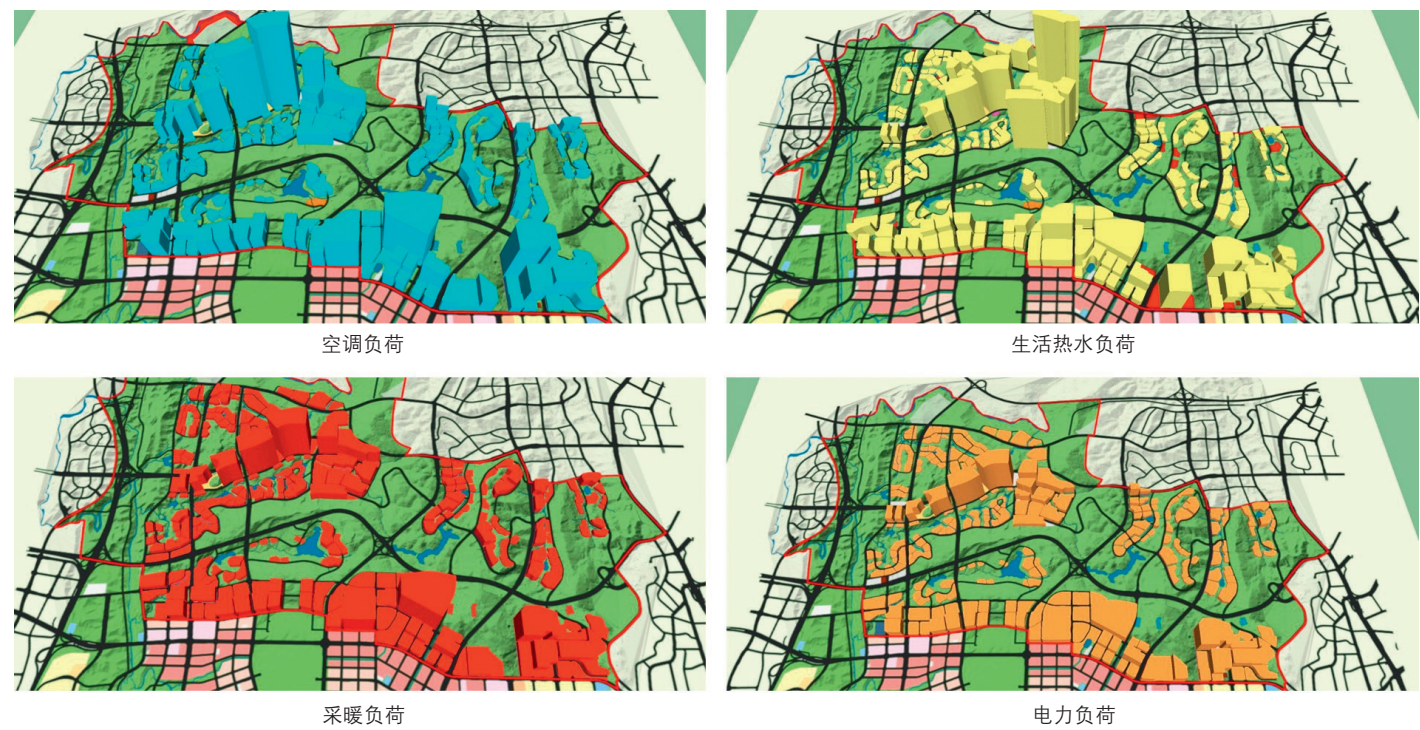

图 7 能源需求分析 
响因子进行综合分析和评分, 并在图纸上精准落位, 形成指 导空间建设的有效依据。

\subsection{2 基于 ArcGIS 和 Fragstats 技术支持的生态效益指数}

首先, 对现状进行生态敏感性分析。运用麦克哈格的千 层饼模式对景观生态的 5 个构成要素进行评价, 包括生态林 地、保护性资源、地表水资源、地质灾害敏感性及高程要素。 根据各个要素的资源重要性和敏感度以及对人类生产活动影 响程度的不同, 赋予相应的权重, 通过叠加、运算和判断, 最终形成生态敏感性的评判结果。通过 “分位数” 的分类方 法将结果分为五级敏感区, 不同分区的建设适宜性不同, 对 应不同的建设强度方案。

另外, 从维护生物多样性的角度对现状进行整体生态效 益分析。以景观生态学为理论依据, 制定相关要素指标, 包 括生境优先级、生境类型多样性、生态敏感性、复层结构、 植物物种组成、斑块要素、廊道要素、生境连接度、生境一 致性、生境边界和边缘效应。通过这些基本单元的结构组合 特征, 量化分析用地方案格局, 获得生态保护控制区的空间 边界, 研究格局与过程之间的相互作用和影响, 计算得出场 地整体规划前后的生态效益结果（图 9, 图 10)。

最后, 根据景观生态学理论中 “斑块一廊道一基质” 构 建生态景观空间网络格局, 结合生态敏感性分析、整体生态 效益控制、最小阻力模型分析、廊道定量分析等手段确定规 划区内重要的生态廊道形态。

将以上分析要素叠加, 最终形成整个山地生态安全格局 建设的空间控制底图，指导下一阶段的空间设计。

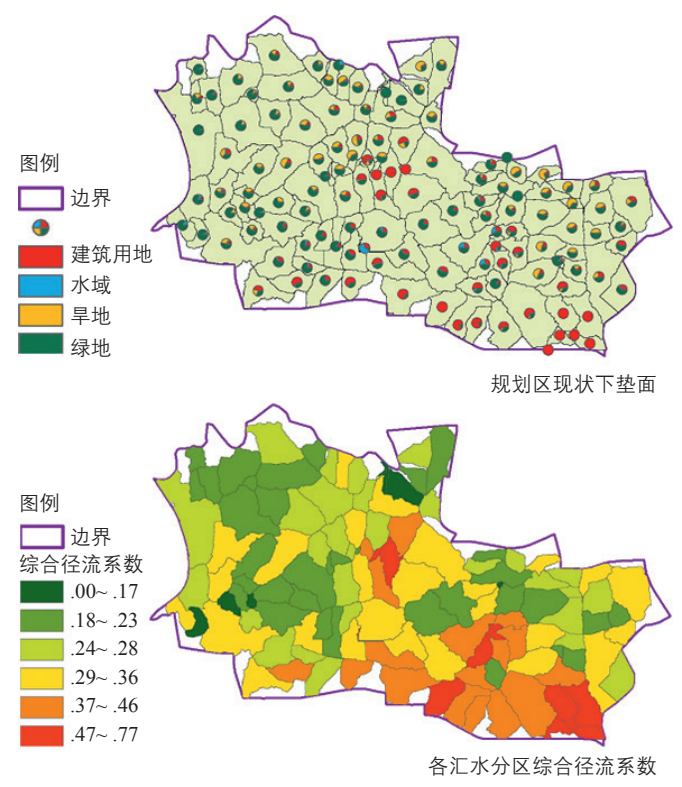

\section{7 数字化绩效评估体系}

采用 KPI 目标导向的数字化绩效评估体系, 基于各项专 业技术指标集成, 进行数字化、动态化、定量分析; 并将评 估结果反馈至设计、管理和维护系统, 形成动态、良性循环。 紧扣科技城发展目标, 以城市功能、景观空间、资源环境为 基础, 在生态空间、环境质量、用地、建筑与能源、城市功能、 制度保障六个方面构建一级指标 6 个。在每个一级指标内部, 拆解目标内涵, 分解子目标, 构建二级指标 16 个, 三级指 标 25 项。在指标设置的过程中, 定性与定量要求互相结合, 整体对应未来建设要求和管理原则（表 1 ）。

\section{4 结语}

城市设计是一项非常复杂的工作, 数字技术提供了广泛 的应用可能性。本次实践尝试将数字化方法纳人设计流程, 构建设计目标参数, 以参数模型构建主导设计过程, 并将设 计结果量化。最终成果除了方案图, 最重要的是一系列的综 合指标, 它们可直接量化数字化设计的效益（表 2)。

在新型城镇化战略的引导下, 回顾城市化进程中走过的 曲折弯路, 营造生态友好、宜居乐业、节能环保、风貌优 美、安全韧性的城市, 已经日益成为共识。为实现这些目 标和诉求, 以科学和理性的态度指导研究实践, 可以少走 弯路; 以工匠思维、精细化设计为支撑, 可以有效逼近目 标。适逢知识经济时代, 多学科数字技术在城市设计领域 的综合应用尽管刚刚起步, 却已显示出强大的生命力。在 未来更多的研究和实践当中, 还可探索引人更多的工程技 术, 如热工环境模拟、声环境模拟等; 探索引人人文社会

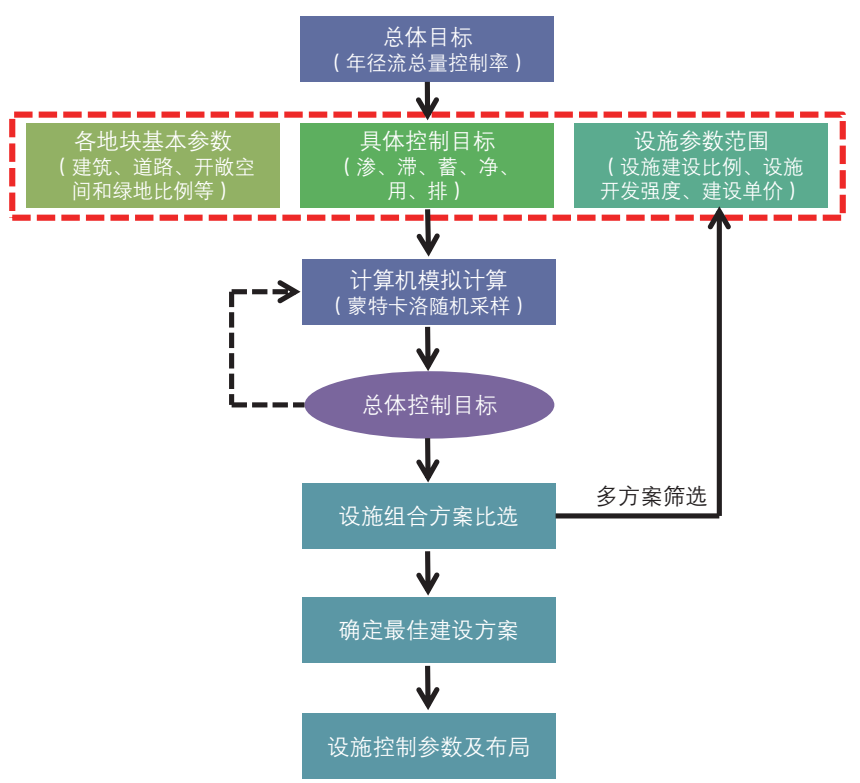

图 8 雨洪管理方案图 

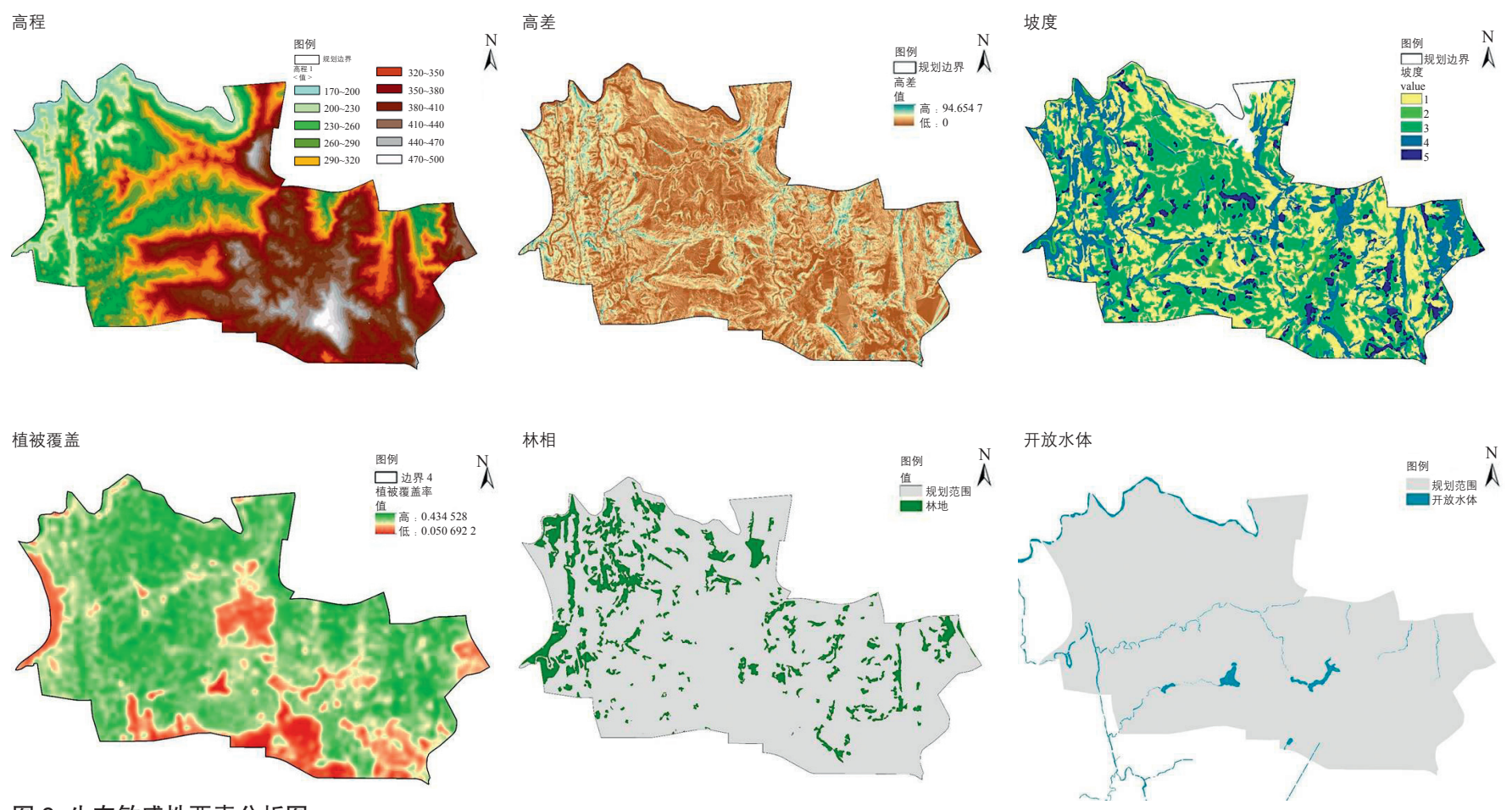

图 9 生态敏感性要素分析图

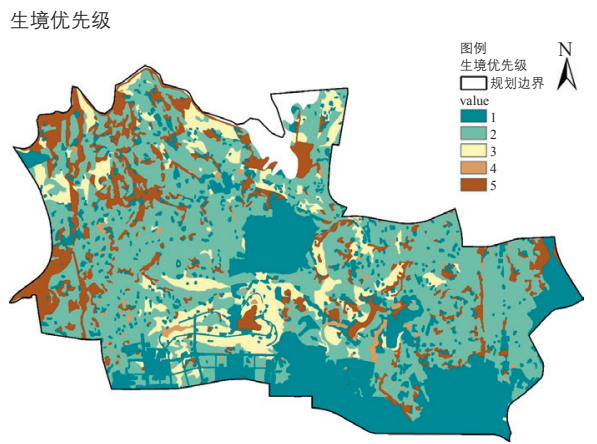

植物物种组成

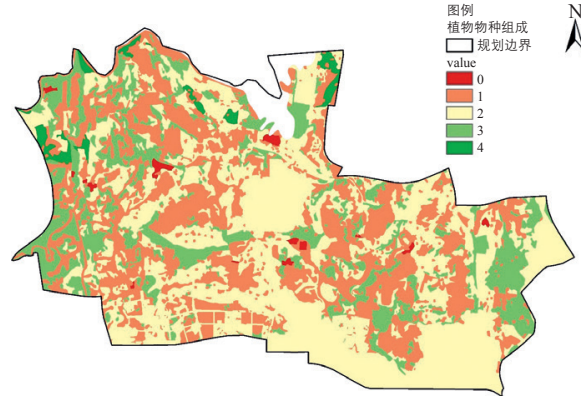

景观复层结构

斑块的形状和大小

生境交错带

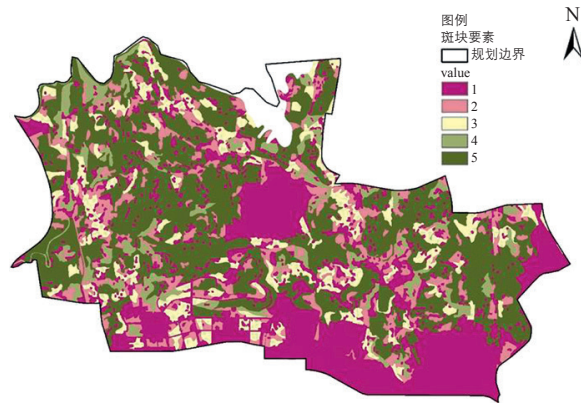

通过形状和大小评价斑块内部生境

岛屿生物地理学理论指出, 物种多样性随着斑块面积的增加 而增加

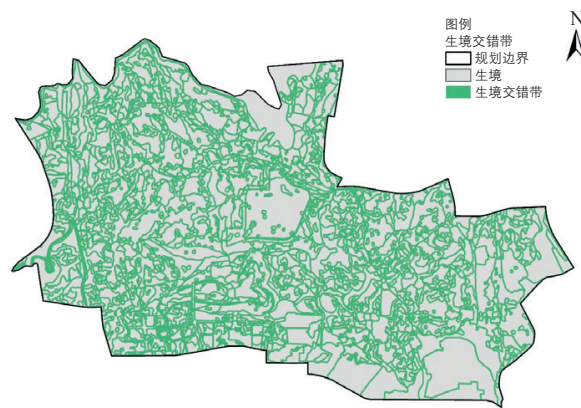

评估交错地带的生态效益

斑块周界常具有较高的物种丰富度和初级生产力; 斑块边缘 具有过滤功能, 可减缓外界对斑块的影响

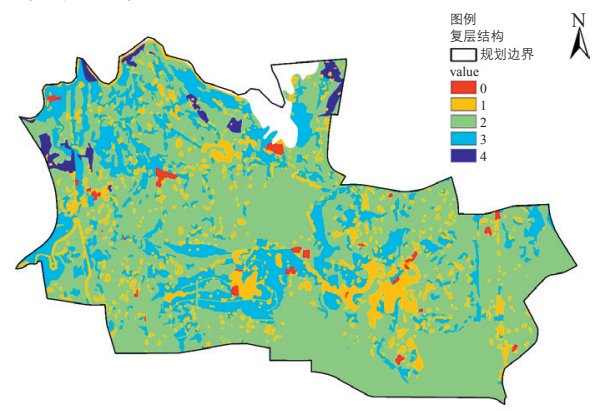

图 10 生态效益要素分析图 
表 1 KPI 指标

\begin{tabular}{|c|c|c|c|c|c|}
\hline \multirow{2}{*}{ 二级指标 } & \multirow{2}{*}{ 序号 } & \multirow{2}{*}{ 三级指标 } & \multicolumn{3}{|c|}{ 指标落实的阶段 } \\
\hline & & & 规划阶段 & 建设阶段 & 运营阶段 \\
\hline \multirow{4}{*}{ 构建山水景观格局 } & 1 & 生态化河道驳岸 100\% & & & \\
\hline & 2 & 主要河流（后河、花石沟）两侧防护距离 $\geqslant 10 \mathrm{~m}$ & & & \\
\hline & 3 & 主要观景点之间保证视线廊道畅通, 能够观赏到较为完整的山体 & & & \\
\hline & 4 & 城市绿地率 $\geqslant 21 \%$ & & & \\
\hline \multirow{3}{*}{ 保护复杂敏感生境 } & 5 & 精细化土地整治, 最大限度减少挖填土方量 & & & \\
\hline & 6 & 生态廊道宽度 $\geqslant 12 \mathrm{~m}$ & & & \\
\hline & 7 & 本地植物指数 $\geqslant 0.8$ & & & \\
\hline \multirow{2}{*}{ 建设低影响海绵城市 } & 8 & 非传统水源利用率 $\geqslant 20 \%$ & & & \\
\hline & 9 & 年雨水径流控制率 $\geqslant 80 \%$ & & & \\
\hline 清洁的大气环境 & 10 & PM2.5 年均浓度 $\leqslant 50 \mu \mathrm{g} / \mathrm{m}^{3}$ & & & \\
\hline 清洁的水环境 & 11 & 地表水水质综合达标率 100\% & & & \\
\hline 宜人的声环境 & 12 & 区域环境噪声平均值 $\leqslant 55$ 分贝 & & & \\
\hline 合理混合开发利用 & 13 & 城市混合使用功能建设用地面积比例 $\geqslant 10 \%$ & & & \\
\hline 科学控制开发强度 & 14 & 缓冲建设区综合容积率 $\leqslant 1.0$ & & & \\
\hline 建设节能绿色建筑 & 15 & 新建建筑一星级及以上绿色建筑比例 100\% & & & \\
\hline \multirow{2}{*}{ 低碳高效能源利用 } & 16 & 可再生能源利用率 $\geqslant 10 \%$ & & & \\
\hline & 17 & 年 $\mathrm{CO}_{2}$ 减排量 $\geqslant 10$ 万吨 $\mathrm{CO}_{2}$ & & & \\
\hline 便利工作环境 & 18 & 搭建共享的交流平台、灵活自由的创新空间 & & & \\
\hline \multirow{2}{*}{ 宜居生活环境 } & 19 & 建设以工作场所为核心的 15 分钟生活圈 & & & \\
\hline & 20 & 教育、医疗、养老等公共服务设施 $1000 \mathrm{~m}$ 半径覆盖率 100\% & & & \\
\hline \multirow{2}{*}{ 绿色出行环境 } & 21 & 建立高效绿色的对外交通联系， $400 \mathrm{~m}$ 公交站点覆盖率 100\% & & & \\
\hline & 22 & 建立全域覆盖的友好步行网络, 慢行道路网密度 $\geqslant 6 \mathrm{~km} / \mathrm{km}^{2}$ & & & \\
\hline 健康的休闲设施 & 23 & 社交、康体、郊野休闲设施 500 m 半径覆盖率 100\% & & & \\
\hline 管理机制健全 & 24 & 建立管理机构、适宜园区发展方向的管理办法 & & & \\
\hline 智能化管理水平 & 25 & 信息化管理设备覆盖建筑比例 100\% & & & \\
\hline
\end{tabular}

\section{表 2 数字化城市设计的综合效益}

\begin{tabular}{|c|c|c|}
\hline \multirow{4}{*}{$\begin{array}{l}\text { 对规划区场地特征的精准 } \\
\text { 利用 }\end{array}$} & 生态效益 & TEB $2.59^{*}$ \\
\hline & 场地竖向 & 填挖方工程量减少约 53\%, 减少工程造价约 26.7 亿元 \\
\hline & 雨水径流 & 雨水净流控制率 $80 \%$; 非传统水源利用率 23\% \\
\hline & 节能减排 & $\begin{array}{l}\text { 年 } \mathrm{CO}_{2} \text { 排放量降低约 } 25.3 \text { 万吨 }(25 \%) \text {; 年 } \mathrm{SO}_{2} \text { 排放量降低约 } 819 \text { 吨 }(23 \%) \text {; } \\
\text { 年 } \mathrm{NO}_{\mathrm{x}} \text { 排放量降低约 } 710 \text { 吨 }(22 \%)\end{array}$ \\
\hline \multirow{3}{*}{$\begin{array}{l}\text { 满足创新阶层生活方式的 } \\
\text { 空间组织 }\end{array}$} & 满足创新阶层工作特征 & $\begin{array}{l}\text { 非正式的交流空间 +创新氛围营造 ; 共享的创新交流平台 ; } \\
\text { 灵活自由的创新空间 ; 多层次的设施和资源共享 }\end{array}$ \\
\hline & 满足创新阶层生活特征 & $\begin{array}{l}\text { 工作场所为核心的 } 15 \text { 分钟生活圈 ; 针对不同人群特质的定制化居所 ; } \\
\text { 具有国际教育医疗水平的全龄关怀社区 ; 完善的运动和文化设施植人 }\end{array}$ \\
\hline & 满足创新阶层出行特征 & $\begin{array}{l}\text { 高效的对外交通联系; 快捷的内外交通衔接; } \\
\text { 加强和完善公共交通体系; 友好的绿色步行网络 }\end{array}$ \\
\hline
\end{tabular}

注: ${ }^{*}$ TEB (Total Ecological Benefit) 即整体生态效益, 评分区间为 $1 \sim 5: 1$ 为生态效益低, 相当于一般城市建成区水平; 2 为较低; 3 为良, 相当 于城市外围郊野地区; 4 为优良, 相当于自然风景区; 5 为高, 相当于热带雨林生态水平。重庆前沿科技城现状未开发状态下 TEB 得分为 2.67 , 传统设计方案 TEB 得分仅为 1 左右。本次采用精细化的生态设计手段, 方案 TEB 得分为 2.59 , 实现了生态低影响开发目标。 
学科, 如历史地理、经济地理、公共管理、社会学等; 探 索引人现代信息科技，如人工智能、城市信息模型（CIM： City Information Model) 系统等。让这些学科和技术为城市 设计贡献更多的活力, 共同推动我国城市设计学科建设和 前沿实践走向世界舞台。UPI

\section{注：文中图表来自参考文献 [15]。}

感谢清华大学建筑学院尹稚教授, 清华同衡规划设计研究 院袁昕、王晓东、恽爽、胡洁几位院长对重庆前沿科技城项目 的悉心指导; 感谢清华同衡规划设计研究院总体规划中心、详 细规划中心、风景园林中心、生态城市研究所、清控人居环境 研究院、交通规划设计研究所、建筑环境与能源研究所、市政 规划研究所、智慧城市所、战略发展与技术应用研究中心等各 相关部所在该项目中的通力协作!

\section{参考文献}

[1] 伊恩 - 论诺克斯 - 麦克哈格. 设计结合自然 [M]. 苪经纬, 译. 天津 : 天 津大学出版社, 2006.

[2] 李苗裔, 王鹏. 数据驱动的城市规划新技术: 从 GIS 到大数据 [J]. 国际 城市规划, 2014, 29(6): 58-65.

[3] 曹有新. 数字化技术在 “三坊七巷” 规划与保护中的应用及研究 [J]. 福建建筑, 2009(3): 23-26

[4] 高海峰, 金維. 基于 Skyline三维 GIS 城市规划辅助决策系统的设计与 实现 [J]. 科技创新与应用, 2012(3): 20-21。

[5]蔡凌豪. 风景园林规划设计的数字实践—以北京林业大学学研中心 景观为例 [J]. 中国园林, 2015, 31(7): 15-20.

[6]陈学楷. 基于虚拟现实技术的工业遗产数字化路径研究 [J]. 艺术科技, 2016, 29(12): 79.

[7] 杨俊宴, 张涛, 谭瑛. 城市风环境研究的技术演进及其评价体系整合 [J]. 南方建筑, 2014(3): 31-38

[8] 赵珂, 于立. 大规划: 大数据时代的参与式地理设计 [J]. 城市发展研究, 2014, 21(10): 28-32.

[9] 郑晓华, 陈韶龄. 南京河西低碳生态城指标体系的构建与实践 [J]. 规划 师, 2013, 29(9): 71-76.

[10] 杨俊宴. 设计蓝图到管理平台: 城市设计的数字化转译 [C]. 第十一届 规划信息化实务论坛, 2017 .

[11] 杨滔. 数字城市与空间向法: 一种数字化规划设计途径 [J]. 规划师, 2012, 28(4): 24-29.

[12] MCGRATH Brian. 城市设计的数字建模 [M]. 电子工业出版社, 2013 .

[13] DERIX Christian. Digital masterplanning: computing urban design[J]. Urban Design and Planning, 2012(12): 203-217.

[14] LLABRES Enriqueta, RICO Eduardo. In progress: relational urban models[J]. Urban Design International, 2012, 17(4): 319-335.

[15] 北京清华同衡规划设计研究院有限公司. 重庆前沿科技城详细规划设 计成果 [Z]. 2015.

[16] PALAZZO Danilo, STEINER Frederick. Urban ecological design: a process for regenerative places[M]. Island Press, 2011.

[17] 蔡凌豪. 凤景园林数字化规划设计概念谱系与流程图解 [J]. 风景园林, 2013(1): 48-57.

[18] The Sustainable Sites Initiative SITES. SITES rating system and scorecard[EB/OL]. (2016-05-10)[2017-08-30]. http://go.usgbc.org/SITES Rating-System-and-Scorecard-Registration.html.

[19] 郭湧. 面向可持续性场地设计的风景园林信息模型前景展望 [J]. 生态
城市与绿色建筑, 2014(4): 62-65.

[20] 邢薇, 赵冬泉, 陈吉宁, 等. 基于低影响开发 (LID) 的可持续城市雨 水系统 [J]. 中国给水排水, 2011, 27(20): 13-16.

[21] 陈小龙, 赵冬泉, 盛政, 等. DigitalWater 在城市排水防涝规划中的应 用 [J]. 中国给水排水, 2015, 31(21): 105-108.

[22] 杨俊宴, 吴浩, 金探花.中国新区规划的空间形态与尺度肌理研究 [J]. 国际城市规划, 2017, 32(2): 34-42.

[23] 毛羽, 杨军, 尹稚。以精细化为核心的中高强度山地城市低影响开发 规划实践 [C]. 国际城市低影响开发 (LID) 学术大会, 2016.

(本文编辑：张祎娴)

\section{( 上接 27 页)}

org/Sociology.Sociology History.

[11] RICHARD B P. Density and urban sprawl[J]. Land Economics, 1989, 65, 193-204.

[12] YANG J. Spatial and social characteristics of urban transportation in Beijing[J]. Transportation Research Record: Journal of the Transportation Research Board, 2010, 2193, 59-67.

[13] ZHAO P. The impact of the built environment on bicycle commuting: evidence from Beijing. Urban Studies, 2014, 51(5), 1019-1037.

[14] GUAN C, PEISER R B. Accessibility, urban form, and property value: toward a sustainable urban spatial structure[C]. Manuscript submitted for publication, 2017.

[15] LYNCH K. The city image and its elements[M]// The Image of the City, 1960: 46-90. http://doi.org/10.1525/sp.1960.8.3.03a00190.

[16] GLAESER E L, KOLKO J , SAIZ A. Consumer city[J]. Journal of Economic Geography, 2001, 1(1): 27-50. http://doi.org/10.1093/jeg/1.1.27.

[17] NEIL B. Decoding the newest "Metropolitan regionalism" in the USA: a critical overview[J]. Cities, 2002, 19(1): 3-21. http://doi.org/10.1016/S02642751(01)00042-7.

[18] 潘斌. 验证凯文・林奇 “形态核心价值标准理论”一以上海江湾一 五角场地区为例 [J]. 国际城市规划, 2008, 23(3): 115-119

[19] BATTY M. 20 years of quantitative geographical thinking[J]. Environment and Planning B: Planning and Design, 2016, 43(4): 605-609. http://doi. org $/ 10.1177 / 0265813516655408$.

[20] PANKAJ G. World 3.0. Global prosperity and how to achieve it[M]. Harvard Business Review Press, 2013.

[21] HEYWOOD D, IAN S C, CARVER S. An introduction to geographical information systems[M]. New York: Addison Wesley Longman, 1998.

[22] WANG D, ZHOU M. The built environment and travel behavior in urban China: a literature review[J]. Transportation Research Part D: Transport and Environment, 2017, 52, 574-585. http://doi.org/10.1016/ j.trd.2016.10.031.

[23] GUAN C, SRINIVASAN S, NIELSON C. Does neighborhood urban form influence non-motorized transport? toward walkable low-carbon cities. Working paper, 2017 